\title{
CMEARTICLE
}

\section{Management of the heart failure patient in the primary care setting}

Weiliang $\underline{\text { Huang}}{ }^{1}$, MBBS, MRCP, Shao Guang Sheldon $\underline{\operatorname{Lee}}{ }^{1}$, MBBS, MRCP, Choon How $\underline{H o w}^{2,3}$, MMed, FCFP

\begin{abstract}
Mdm Teo Ah Mui, an 88-year-old woman, visited your clinic for her regular follow-up, as she had done for the past 20 years. She had just been discharged from the hospital after being admitted for an episode of heart failure last month. She asked about her new medications to protect her heart and regulate her fluid status, wanting to know if they were indeed good for her.
\end{abstract}

\section{WHAT IS HEART FAILURE?}

Heart failure (HF) is a clinical syndrome comprising signs and symptoms that result from a structural or functional cardiac abnormality, causing a compromise in cardiac output and/or elevated intracardiac filling pressures at rest or stress. ${ }^{(1)}$ It is the result of any insult, such as coronary, valvular or arrhythmic, causing a disturbance to cardiac function.

\section{HOW RELEVANT IS THIS TO MY PRACTICE?}

HF is extremely prevalent in Singapore. About $20 \%$ of deaths in Singapore in 2017 were due to ischaemic heart disease and other cardiac diseases..$^{(2)} 4.5 \%$ of Singaporeans live with HF, compared to $1 \%-2 \%$ in the United States and Europe.

Many Singaporeans are also at risk of HF, with the most prevalent risk factors being insufficient physical activity $(34 \%$ of the population), smoking $(16 \%)$, obesity $(35 \%)$, diabetes mellitus $(10 \%)$ and hypertension (14\%). ${ }^{(3)}$ These risk factors need to be adequately controlled to minimise the chance of developing HF or, in the case of a HF patient, controlled to retard progression of HF. Management of HF requires the patient's involvement and a multidisciplinary team approach (Box 1).

\section{Common signs and symptoms at presentation}

The patient typically develops and presents with fluid overload, which causes dyspnoea, orthopnoea, jugular venous distension, pulmonary crepitations and ankle oedema. ${ }^{(1,6)}$ When there is severely depressed cardiac output, there can be hypotension, cold extremities, decreased urine output and altered mentation when the cardiac output is unable to support adequate tissue perfusion. ${ }^{(1)}$ These patients should be promptly referred to the accident and emergency department.

A medical history of cardiovascular disease or cardiovascular risk factors makes the diagnosis of HF more likely. All stable patients suspected to have newly diagnosed HF should have electrocardiography (ECG) performed and be referred to a cardiologist for early evaluation.

\section{WHAT CAN I DO IN MY PRACTICE?}

After diagnosis, the HF patient should ideally be managed in the community, with follow-up to ensure that the patient has few or no symptoms. Repeated hospitalisations for HF is a strong predictor of mortality. ${ }^{(7)}$

\section{Patient self-care}

Treatment goals should first be discussed and established with the patient, preferably with the support of caregivers and family members.

HF patients should restrict their salt and fluid intake, albeit to varying degrees based on the individual patient's profile and severity of HF. They should be counselled on smoking cessation and avoidance of alcohol (especially for alcoholrelated cardiac dysfunction), and screened for depression and managed accordingly. ${ }^{(8)}$ Patients should also be taught self-care, symptom surveillance and weight monitoring, and advised to purchase a suitable water jug (e.g. 1-L jug) specifically for regulating water intake and a reliable weighing machine for daily weight measurements and recording. They should try as much as possible to comply with the fluid restrictions, and monitor themselves closely for symptoms such as ankle swelling if they exceed their restrictions on a hot day. Regular aerobic exercise should be encouraged to improve functional capacity and symptoms. ${ }^{(9)}$

Changes in functional status and/or a rapid gain in weight could herald decompensation. Early intervention, such as by temporarily increasing the diuretic dose, could restore equilibrium and avoid an admission to hospital.

HF patients who are unable to return to previous physically demanding work can be referred to Family Service Centres or Workforce Singapore Career Centres to find suitable employment.

${ }^{1}$ Department of Cardiology, ${ }^{2}$ Care and Health Integration, Changi General Hospital, ${ }^{3}$ Family Medicine Academic Clinical Programme, SingHealth Duke-NUS Academic Medical Centre, Singapore

Correspondence: Dr Huang Weiliang, Associate Consultant, Department of Cardiology, Changi General Hospital, 2 Simei Street 3 , Singapore 529889. huang.weiliang@singhealth.com.sg 
Box 1. Management strategy for a patient with heart failure:

- Involve the patient to set treatment goals - customising and specifying realistic physical goals and social independence to be achieved.

- Optimise functional status and improving activity tolerance, with the ultimate goal of returning to his/her agreed optimal lifestyle.

- Help the patient, especially those whose lifestyle or work involves high physical demands, to modify and explore alternative options with reduced activity tolerance, including finding new work options and arranging help at home if needed.

- Advance care planning.

- Control fluid and salt intake (i.e. daily weight management and charting, salt intake reduction, not adding salt to food).

- Smoking cessation and regular exercise.

- Optimising underlying cardiac risk factors, e.g. diabetes mellitus, hypertension or lipid management, with the primary care doctor.

- Optimising disease-modifying drugs.

- Vaccinating against common ailments that could precipitate heart failure decompensation, e.g. influenza (annual) and pneumococcal vaccines.

- Timely diagnosis and treatment of decompensation to reduce admissions and mortality. ${ }^{(1,4,5)}$

\section{Physician's tasks}

During a routine clinic visit, the physician should document effort tolerance (New York Heart Association [NYHA] class), review weight charts, assess blood pressure and examine the patient's fluid status, as well as assess medication compliance and side effects. The primary care physician also needs to screen HF patients for depression, for which the Patient Health Questionnaire-9 is a useful tool. ${ }^{(8)}$ HF patients should receive an annual influenza vaccination and a course of pneumococcal vaccination. Advance care planning, as well as work placement and financial help, should be discussed if required.

The dose of diuretics, usually oral frusemide, is patientdependent (usually affected by cardiac and renal function) and, if required, can be increased temporarily to deal with decompensation episodes, such as doubling the dose for short periods with frequent re-assessment. Disease-modifying drugs for chronic HF are prescribed and titrated based on the patient's left ventricular ejection fraction (LVEF). Patients are divided into HFrEF (HF with reduced ejection fraction $<40 \%$ ), HFpEF (HF with preserved ejection fraction $\geq 50 \%$ ) and HFmrEF (HF with mid-range ejection fraction $40 \%-49 \%$ ) groups based on their LVEF on echocardiography.

\section{HFrEF (HF with reduced ejection fraction < 40\%)}

While many evidence-based disease-modifying drugs are available for the treatment of chronic HF, HFrEF patients are notoriously undertreated. ${ }^{(3)}$ An angiotensin-converting enzyme (ACE) inhibitor (or angiotensin receptor blocker [ARB]) $)^{(10)}$ and beta-blocker ${ }^{(11)}$ are recommended for a patient with symptomatic (NYHA Class II-IV) HFrEF. A mineralocorticoid receptor antagonist ${ }^{(12)}$ is recommended in symptomatic patients with LVEF $\leq 35 \%$. These drugs should be administered at the target dose as long as the patient does not experience symptomatic hypotension (i.e. blood pressure remains $>90 / 60 \mathrm{mmHg}$ ). Starting at a lower dose with judicious up-titration could help encourage acceptance and minimise adverse drug effects. Should the patient still have HF symptoms, the ACE inhibitor (or ARB) can be replaced with an angiotensin receptor-neprilysin inhibitor (ARNI). The PARADIGM-HF trial showed that sacubitril/valsartan (an ARNI) is superior to enalapril in reducing morbidity and mortality in HFrEF patients. ${ }^{(13)}$ Renal function, and in particular potassium levels, should be monitored 1-2 weeks after initiation or dosage change, then 3-6 monthly in patients on ACE-inhibitor/ARB/ ARNI to ensure stability.

Beta-blockers are the first-line therapy in controlling the heart rate of a patient with chronic HFrEF. A target heart rate of 50-70 beats per minute (bpm) is advised. Adding an $I_{\text {f-channel blocker }}$ is reasonable if the patient is in sinus rhythm and has a heart rate that is persistently $>70 \mathrm{bpm}$ despite being on the maximum tolerated dose of beta-blocker. ${ }^{(14)}$

For diabetic patients with HFrEF, metformin ${ }^{(15)}$ and a sodiumglucose cotransporter-2 (SGLT-2) inhibitor ${ }^{(16)}$ should be included in their drug regimen. Both the EMPA-REG OUTCOME trial ${ }^{(17)}$ and DECLARE-TIMI 58 trial $^{(18)}$ showed significant mortality and morbidity benefit of SGLT-2 inhibitors over placebo in HFrEF patients. However, thiazolidinediones, ${ }^{(19)}$ saxagliptin, ${ }^{(20)}$ nonsteroidal anti-inflammatory drugs and COX-2 inhibitors ${ }^{(21)}$ are not recommended in HF patients.

An automated implanted cardioverter-defibrillator device should be considered in patients with LVEF $\leq 35 \%$ and NYHA Class II-III after optimising medical therapy for prevention of sudden cardiac death. ${ }^{(22)}$ Cardiac resynchronisation therapy should be considered in symptomatic patients who are in sinus rhythm, with left bundle branch block on ECG, who have QRS duration $\geq 150 \mathrm{~ms}$ and LVEF $\leq 35 \%$ despite optimal medical therapy. ${ }^{(23)}$ Commonly used drugs for HFrEF are shown in Table I.

\section{HFmrEF (HF with mid-range ejection fraction 40\%-49\%)}

Patients with HFmrEF are a distinct group for whom there is currently no evidence-based medication to reduce mortality or morbidity. However, in the recent PARAGON-HF trial, the therapeutic benefits of ARNI vary by LVEF and appear to extend to HFmrEF patients, particularly for hospitalisation for HF. ${ }^{(24)}$

\section{HFpEF (HF with preserved ejection fraction $\geq 50 \%$ )}

$\mathrm{HFpEF}$ is on the rise in Southeast Asia due to the high prevalence of rapidly ageing societies and hypertension. ${ }^{(3)}$ Compared to HFrEF, HFpEF patients tend to be older and female, have hypertension and atrial fibrillation, and less likely to have myocardial infarction. ${ }^{(25)}$

Currently, no specific pharmacological treatment has been shown to reduce mortality and morbidity in HFpEF patients. Several studies are ongoing. The current aim of treatment is to alleviate symptoms and improve quality of life, such as by prescribing diuretics to congested patients, ${ }^{(1,26)}$ as well as aggressive control of comorbidities such as hypertension. 
Table I. Commonly used drugs in HFrEF and their appropriate target doses. ${ }^{(1)}$

\begin{tabular}{|c|c|c|}
\hline Drug & Starting dose & Target dose \\
\hline \multicolumn{3}{|l|}{ ACE inhibitor } \\
\hline Captopril & $6.25 \mathrm{mg}$ TDS & $50 \mathrm{mg}$ TDS \\
\hline Enalapril & $2.5 \mathrm{mg} \mathrm{BDS}$ & $20 \mathrm{mg} \mathrm{BDS}$ \\
\hline Lisinopril & $2.5 \mathrm{mg} \mathrm{om}$ & $20-35$ mg om \\
\hline Ramipril & $2.5 \mathrm{mg} \mathrm{om}$ & $10 \mathrm{mg}$ om \\
\hline Perindopril & $2 \mathrm{mg} \mathrm{om}$ & $8 \mathrm{mg} \mathrm{om}$ \\
\hline \multicolumn{3}{|l|}{ Beta-blocker } \\
\hline Bisoprolol & $1.25 \mathrm{mg} \mathrm{om}$ & $10 \mathrm{mg}$ om \\
\hline Carvedilol & $3.125 \mathrm{mg}$ BDS & $25 \mathrm{mg}$ BDS \\
\hline \multicolumn{3}{|l|}{ ARB } \\
\hline Candesartan & $4 \mathrm{mg}$ om & $32 \mathrm{mg}$ om \\
\hline Valsartan & $40 \mathrm{mg} \mathrm{BDS}$ & $160 \mathrm{mg}$ BDS \\
\hline Losartan & $50 \mathrm{mg}$ om & $150 \mathrm{mg}$ om \\
\hline Telmisartan & $40 \mathrm{mg}$ om & $80-160 \mathrm{mg}$ om \\
\hline \multicolumn{3}{|c|}{ Mineralocorticoid receptor antagonist } \\
\hline Eplerenone & $25 \mathrm{mg}$ om & $50 \mathrm{mg} \mathrm{om}$ \\
\hline Spironolactone & $25 \mathrm{mg}$ om & $50 \mathrm{mg}$ om \\
\hline \multicolumn{3}{|l|}{ ARNI } \\
\hline Sacubitril/valsartan & 49/51 mg BDS & 97/103 mg BDS \\
\hline \multicolumn{3}{|l|}{$I_{f}$-channel blocker } \\
\hline Ivabradine & $5 \mathrm{mg}$ BDS & $7.5 \mathrm{mg}$ BDS \\
\hline
\end{tabular}

ACE: angiotensin-converting enzyme; ARB: angiotensin receptor blocker ARNI: angiotensin receptor-neprilysin inhibitor; BDS: twice daily; HFrEF (heart failure with reduced ejection fraction $<40 \%$ ); om: every morning; TDS: three times a day

In conclusion, HF is a common problem in Singapore and requires a multidisciplinary approach. A combination of appropriate disease-modifying drugs, lifestyle modifications, and accessibility to care can help to reduce morbidity and hospitalisation rates.

\section{TAKE HOME MESSAGES}

1. Newly diagnosed, clinically stable HF patients require early specialist evaluation, while unstable or hypotensive patients need emergency attention.

2. Treatment goals should be discussed and agreed on with patients before being clearly documented in a care plan.

3. Decompensation should be detected early and treated with a temporary increase in diuretics.

4. Fluid and salt restrictions should be encouraged and enforced, with measurement of fluid intake and daily weight.

5. Smoking cessation and regular exercise should be encouraged.

6. Patients with HF should receive influenza and pneumococcal vaccines.

7. Patients can be screened for depression at clinic visits.

8. Diabetes mellitus, hypertension and lipid control should be optimised.

9. In patients with in HFrEF, disease-modifying drugs should be optimised to achieve appropriate target doses or at least maximally tolerated doses.
10. Patients should be encouraged to re-integrate into society with help from community resources.

\section{USEFUL LINKS}

- Workforce Singapore: https://www.ssg-wsg.gov.sg (accessed April 16, 2020)

- $\quad$ Advance care planning: https://www.livingmatters.sg (accessed April 16, 2020)

- $\quad$ Family Service Centres: https://www.msf.gov.sg/dfcs/ familyservice (accessed April 16, 2020)

Mdm Teo was happy to learn what her two new medications - beta-blockers and ACE inhibitors were for. Her domestic helper, Mary, would help to prepare a small 1- $L$ water flask and monitor her fluid intake, chart her weight daily and remind her to take her medications. You also reminded Mary to chart Mdm Teo's diet and drop by your clinic 2-3 days later after her morning walk to hand her charts to your clinic assistants.

\section{REFERENCES}

1. Ponikowski P, Voors AA, Anker SD, et al; Authors/Task Force Members; Document Reviewers. 2016 ESC Guidelines for the diagnosis and treatment of acute and chronic heart failure: the task force for the diagnosis and treatment of acute and chronic heart failure of the European Society of Cardiology (ESC). Developed with the special contribution of the Heart Failure Association (HFA) of the ESC. Eur J Heart Fail 2016; 18:891-975.

2. Ministry of Health, Singapore. Principal Causes of Death. Available at: https:// www.moh.gov.sg/resources-statistics/singapore-health-facts/principal-causesof-death. Accessed April 15, 2020.

3. Lam CSP. Heart failure in Southeast Asia: facts and numbers. ESC Heart Failure 2015; 2:46-9.

4. Cleland JG, Cohen-Solal A, Aguilar JC, et al; IMPROVEMENT of Heart Failure Programme Committees and Investigators. Improvement programme in evaluation and management; Study Group on Diagnosis of the Working Group on Heart Failure of The European Society of Cardiology. Management of heart failure in primary care (the IMPROVEMENT of Heart Failure Programme): an international survey. Lancet 2002; 360:1631-9.

5. Feltner $\mathrm{C}$, Jones $\mathrm{CD}$, Cené $\mathrm{CW}$, et al. Transitional care interventions to prevent readmissions for persons with heart failure: a systematic review and metaanalysis. Ann Int Med 2014; 160:774-84.

6. Vijayakrishnan R, Steinhubl SR, Ng K, et al. Prevalence of heart failure signs and symptoms in a large primary care population identified through the use of text and data mining of the electronic health record. J Card Fail 2014; 20:459-64.

7. Lin AH, Chin JC, Sicignano NM, Evans AM. Repeat hospitalisations predict mortality in patients with heart failure. Mil Med 2017; 182:e1932-e1937.

8. National Institute for Health and Clinical Excellence Chronic heart failure: management of chronic heart failure in adults in primary and secondary care [online]. NICE clinical guideline 108. Available at: http://www.wales.nhs.uk/ sitesplus/documents/861/NICE\%20Guidelines\%20-\%20Chronic\%20Heart\%20 Failure.pdf. Accessed April 15, 2020

9. Ismail H, McFarlane JR, Nojoumian AH, Dieberg G, Smart NA. Clinical outcomes and cardiovascular responses to different exercise training intensities in patients with heart failure: a systematic review and meta-analysis. JACC Heart Fail 2013; 1:514-22.

10. Garg R, Yusuf S. Overview of randomized trials of angiotensin-converting enzyme inhibitors on mortality and morbidity in patients with heart failure. Collaborative Group on ACE Inhibitor Trials. JAMA 1995; 273:1450-6.

11. Hjalmarson A, Goldstein S, Fagerberg B, et al. Effects of controlled-released metoprolol on total mortality, hospitalizations, and well-being in patients with heart failure: the Metoprolol CR/XL Randomized Intervention Trial in congestive heart failure (MERIT-HF). MERIT-HF Study Group. JAMA 2000; 283:1295-302.

12. Pitt B, Zannad F, Remme WJ, et al. The effect of spironolactone on morbidity and mortality in patients with severe heart failure. Randomized Aldactone Evaluation Study Investigators. N Engl J Med 1999; 341:709-17. 
13. McMurray JJ, Packer M, Desai AS, et al; PARADIGM-HF Investigators and Committees. Angiotensin-neprilysin inhibition versus enalapril in heart failure. N Engl J Med 2014; 371:993-1004.

14. Swedberg K, Komajda M, Böhm M, et al; SHIFT Investigators. Ivabradine and outcomes in chronic heart failure (SHIFT): a randomised placebo-controlled study. Lancet 2010; 376:875-85.

15. MacDonald MR, Eurich DT, Majumdar SR, et al. Treatment of type 2 diabetes and outcomes in patients with heart failure: a nested case-control study from the U.K. General Practice Research Database. Diabetes Care 2010; 33:1213-8

16. Seferovć PM, Petrie MC, Filippatos GS, et al. Type 2 diabetes mellitus and heart failure: a position statement from the Heart Failure Association of the European Society of Cardiology. Eur J Heart Fail 2018; 20:853-72.

17. Zinman B, Wanner C, Lachin JM, et al; EMPA-REG OUTCOME Investigators Empagliflozin, cardiovascular outcomes, and mortality in type 2 diabetes. N Engl J M 2015; 373:2117-28.

18. Wiviott SD, Raz I, Bonaca MP, et al; DECLARE-TIMI 58 Investigators Dapagliflozin and cardiovascular outcomes in type 2 diabetes. N Engl J Med 2019; 380:347-57.

19. Hernandez AV, Usmani A, Rajamanickam A, Moheet A. Thiazolidinediones and risk of heart failure in patients with or at high risk of type 2 diabetes mellitus: meta-analysis and meta-regression analysis of placebo-controlled randomized clinical trials. Am J Cardiovasc Drugs 2011; 11:115-28.
20. Scirica BM, Bhatt DL, Braunwald E, et al; SAVOR-TIMI 53 Steering Committee and Investigators. Saxagliptin and Cardiovascular Outcomes in Patients with type 2 diabetes mellitus. N Engl J Med 2013; 369:1317-26.

21. Scott PA, Kingsley GH, Scott DL. Non-steroidal anti-inflammatory drugs and cardiac failure: meta-analyses of observational studies and randomised controlled trials. Eur J Heart Fail 2008; 10:1102-7.

22. Theuns DA, Smith T, Hunink MG, Bardy GH, Jordaens L. Effectiveness of prophylactic implantation of cardioverter-defibrillators without cardiac resynchronization therapy in patients with ischaemic or non-ischaemic heart disease: a systematic review and meta-analysis. Europace 2010; 12:1564-70.

23. Cleland JG, Daubert JC, Erdmann E, et al; Cardiac Resynchronization-Heart Failure (CARE-HF) Study Investigators. The effect of cardiac resynchronization on morbidity and mortality in heart failure. N Engl J Med 2005; 352:1539-49. Owan TE, Hodge DO, Herges RM, et al. Trends in prevalence and outcome of heart failure with preserved ejection fraction. N Engl J Med 2006; 355:251-9.

24. Solomon SD, Vaduganathan M, L Claggett B, et al. Sacubitril/valsartan across the spectrum of ejection fraction in heart failure. Circulation 2020; 141:352-61.

25. Owan TE, Hodge DO, Herges RM, et al. Trends in prevalence and outcome of heart failure with preserved ejection fraction. N Engl J Med 2006; 355:251-9.

26. Lewis EF, Lamas GA, O'Meara E, et al; CHARM Investigators. Characterization of health-related quality of life in heart failure patients with preserved versus low ejection fraction in CHARM. Eur J Heart Fail 2007; 9:83-91. 


\section{SINGAPORE MEDICAL COUNCIL CATEGORY 3B CME PROGRAMME} (Code SMJ 202005A)

1. Hypertension, diabetes mellitus and smoking are known risk factors for heart failure.

2. Heart failure patients must all be followed up by a cardiologist at the hospital.

3. Heart failure patients can present with cold extremities, hypotension and altered mentation.

4. Electrocardiography should be performed for patients with new signs and symptoms suggestive of heart failure.

5. Regular aerobic exercise can improve heart failure symptoms.

6. When a patient goes into fluid overload but is still clinically stable, the physician should increase his/her diuretic dose temporarily and reassess frequently.

7. Heart failure patients should receive influenza and meningococcal vaccines.

8. Bisoprolol is recommended for patients with heart failure with reduced ejection fraction (HFrEF).

9. A heart failure patient with left ventricular ejection fraction (LVEF) $30 \%$ is on lisinopril $2.5 \mathrm{mg}$ om (every morning) and has an average blood pressure of $125 / 80 \mathrm{mmHg}$. His lisinopril dose should be kept at $2.5 \mathrm{mg}$ om.

10. Sacubitril/valsartan has greater mortality benefit than enalapril in HFrEF.

11. A patient with atrial fibrillation on maximum beta-blocker dose and with heart rate persistently $>70$ beats per minute should receive ivabradine.

12. Nonsteroidal anti-inflammatory drugs should not be given to heart failure patients as they could precipitate a heart failure decompensation episode.

13. All heart failure patients should receive an automated implanted cardioverter-defibrillator device to prevent sudden cardiac death.

14. A heart failure patient with LVEF $45 \%$ will not benefit from cardiac resynchronisation therapy.

15. Eplerenone is indicated in all HFpEF patients.

16. For accuracy, heart failure patients should have their weight measured at the clinic visit only.

17. Depression is rare among heart failure patients.

18. Heart failure is classified into HFrEF, HFmrEF (heart failure with mid-range ejection fraction), and HFpEF (HF with preserved ejection fraction) based on echocardiographic findings.

19. Renal function should be monitored in patients who are on angiotensin-converting enzyme inhibitor, angiotensin receptor blocker, angiotensin receptor-neprilysin inhibitor or mineralocorticoid receptor antagonist.

20. All heart failure patients should be advised to stop smoking.

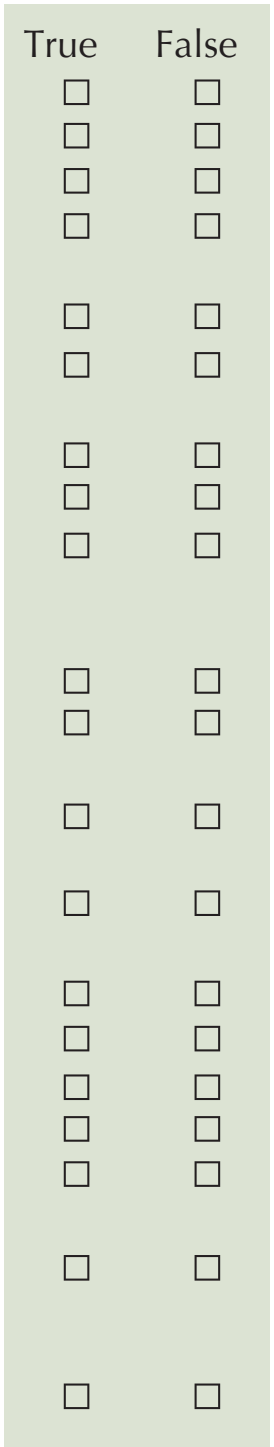

Doctor's particulars:

Name in full:

MCR no:

Specialty:

Email:

\section{SUBMISSION INSTRUCTIONS}

Visit the SMJ website: http://www.smj.org.sg/current-issue and select the appropriate quiz. You will be redirected to the SMA login page.

For SMA member: 1) Log in with your username and password (if you do not know your password, please click on 'Forgot your password?'). (2) Select your answers for each quiz and click 'Submit'.

For non-SMA member: (1) Create an SMJ CME account, or log in with your SMJ CME username and password (for returning users). (2) Make payment of SGD 21.40 (inclusive of $7 \%$ GST) via PayPal to access this month's quizzes. (3) Select your answers for each quiz and click 'Submit'.

RESULTS

(1) Answers will be published online in the SMJ July 2020 issue. (2) The MCR numbers of successful candidates will be posted online at the SMJ website by 8 July 2020. (3) Passing mark is $60 \%$. No mark will be deducted for incorrect answers. (4) The SMJ editorial office will submit the list of successful candidates to the Singapore Medical Council. (5) One CME point is awarded for successful candidates. (6) SMC credits CME points according to the month of publication of the CME article (i.e. points awarded for a quiz published in the May 2020 issue will be credited for the month of May 2020, even if the deadline is in July 2020).

Deadline for submission (May 2020 SMJ 3B CME programme): 12 noon, 1 July 2020. 